\title{
RE-PRESENTANDO A LA VIDA: ARTAUD Y LA POSMODERNIDAD
}

\section{RE-PRESENTING LIFE: ARTAUD AND POSMODERNITY}

\author{
Jonathan Piedra Alegría \\ Universidad Nacional de Costa Rica
}

Recibido: 21 de febrero, $2014 \bullet 11$ de marzo, 2015

Resumen: Este artículo pretende relacionar el pensamiento del actor, escritor y dramaturgo Antonin Artaud con una serie de temas que comúnmente se han asociado a la denominada posmodernidad.

Palabras clave: posmodernidad, teatro, lenguaje, crueldad, Antonin Artaud

Abstract: This paper relates the thought of the actor, writer and dramatist Antonin Artaud, with a series of topics that usually have associated with the denominate postmodernism.

Keywords: Postmodernism, theater, language, cruelty, Antonin Artaud

Allí donde otros proponen obras yo no pretendo otra cosa que mostrar mi espíritu.

La vida es un consumirse en preguntas. No concibo la obra como separada de la vida.

No amo la creación separada...

Antonin Artaud

L'ombilic des limbes 
$\mathrm{L}$

o que hasta ahora ha sido denominado como "posmodernidad" no está muy claro. Se puede decir que el concepto resulta ser, por lo menos, polisémico. Al respecto, se han brindado concepciones que son, como mínimo, bastante diversas; suele decirse, entre otras tantas cosas, que es una ideología, un dato histórico, una condición, una moda y/o una filosofía. Tanto así que no es extraño encontrar los términos posmoderno o posmodernismo en el lenguaje más o menos común, con una carga predominantemente peyorativa y poco precisa.

Un intento de precisión interesante lo realizó la filósofa argentina Esther Díaz (Díaz, 2005). Para ella, la posmodernidad implica una nueva concepción de la cotidianidad con relación a la vivencia de la modernidad. Dentro de esta nueva cosmovisión se encuentran cambios profundos en la ciencia, la ética y, por supuesto, el arte. Lo definitorio de la postura de Díaz es el cambio de un paradigma a otro. No obstante, un dato importante radica en nuestra poca o total falta de consciencia sobre las verdaderas implicaciones de la posmodernidad. La intensidad de los cambios nos impide tomar una conciencia epocal verdadera y profunda. En este sentido, hasta las ciencias más duras no escapan a estos cambios. Por ejemplo, la llamada objetividad científica es replanteada y ahora resulta estar condicionada por relaciones de poder. La "verdad" científica resulta ser solamente una construcción histórico-social.

Asimismo, en cuanto al arte, este ya no tiene pretensiones universales o monumentales, sino que rescata la multiplicidad de códigos y recibe con agradado lo que llama "el legado de las vanguardias estéticas".

La razón absoluta como instrumento emancipador desaparece de la ética, la ciencia y el arte, y ahora se realiza una labor ecléctica muy diversa, producto del desencanto. Todo esto nos brinda una nueva concepción de la cotidianidad que aún no hemos asimilado, precisamente por la naturaleza de estos cambios. Las tecnologías tienen un papel importantísimo en la posmodernidad, pues reformulan nuestra concepción de subjetividad, creando consecuentemente un nuevo concepto de lo cotidiano para un nuevo sujeto.

Sin embargo, y a pesar del carácter difuso del concepto posmodernidad, la mayoría de los autores parecen estar de acuerdo en un punto: la caída de los metarrelatos y las grandes narrativas. Lyotard (1998), por mencionar solo 
a un autor, justificó lo anterior desde la legitimidad de las normas o, para ser más preciso, la legitimidad de los enunciados que sustentan un metarrelato. Siguiendo lo que Wittgenstein llamó los juegos del lenguaje, Lyotard propuso que ningún grupo de enunciados se legitima en sí y por sí mismo, sino que recibe su legitimación de otros enunciados, todo esto dentro de un determinado tipo de discurso. Al igual que los juegos del lenguaje, estos discursos son inconmensurables entre sí. Aquí lo fundamental es el carácter tautológico de los metarrelatos, que precisamente por esto resultan en última instancia indemostrables, y que para justificarlos es necesario recurrir a los mitos. De lo anterior resulta el carácter inapropiado e incorrecto de esta forma de justificar.

Si se sigue este planteamiento se puede considerar el concepto que Hegel brindó de la modernidad como un metarrelato, ya que esta supuesta modernidad comprendería en el discurso dialéctico todos los demás enunciados. En la misma línea se encuentra Jürgen Habermas, quien consideró algo similar. Para él el concepto de modernidad en Hegel puede verse como una metanarrativa. Habermas partió de los escritos del joven Hegel, en los cuales este veía la realidad como una totalidad desgarrada.

De esta manera, la modernidad presenta una serie de contradicciones internas (que se resuelven simbólicamente en el cristianismo protestante), las cuales solo encuentran solución en ella misma, es decir, en la misma modernidad. Según Habermas, lo que Hegel realizó es solo una crítica a la subjetividad dentro de la modernidad. Es por esto mismo que buscó una reconciliación que unificara lo desagarrado, lo cual se llevaría a cabo por medio del saber absoluto. La concepción de modernidad hegeliana vendría a ser, de esta manera, una metanarrativa, ya que todos los enunciados son subsumidos en el discurso de la razón. Una razón que resulta ser mítica y todopoderosa, cuyos estadios se van desarrollando a lo largo de la historia (Geist). La historia misma resultaría ser una metanarrativa que se ve sustentada por otro metarrelato: el proceso dialéctico de la razón.

Otro punto en el que parece haber cierta unanimidad es en que la posmodernidad implica una transformación en lo concerniente a la estética. La posmodernidad desecha y aborrece las pretensiones estéticas que tienden a la monumentalidad, así como aquellos parámetros rígidos e inflexibles. Francis Jameson (1995) partió de estas premisas para dar a entender que si esto es 
así se debe a la sociedad de consumo y los mass media. Es decir, los cambios estéticos que resguarda la posmodernidad son resultado del capitalismo globalizado. La estética posmoderna "reacciona" frente al elitismo y el estilo único de la modernidad con el populismo del arte (consecuencia directa de la sociedad de consumo) y un eclecticismo artístico. En esta concepción la vuelta al pasado y la nostalgia por lo antiguo no son desechadas o rechazadas, sino que son incorporadas por la nueva sensibilidad posmoderna. Las obras no pretenden ser originales y solamente son consideradas como arte si la sociedad dice que son arte. ${ }^{1}$ Todo esto implica una heterogeneidad discursiva y estética que involucra la desaparición del viejo simbolismo artístico (ahora todo puede significar cualquier cosa), y la obra, lejos de ser una obra per se, se relaciona íntimamente con el espectador, haciendo de alguna manera que todos seamos críticos de arte. Todas estas transformaciones provocan, a su vez, una transformación del espacio urbano. Y este es quizás el aspecto que más recalcó Jameson.

Asimismo, se puede decir que la posmodernidad resulta ser una postura crítica frente a las promesas de la modernidad y no su contrario, como algunos podrían pensar. Los ideales que la modernidad ilustrada buscaban o escudaban un progreso científico y moral de la mano de la todopoderosa razón. Los fanatismos o misticismos religiosos deberían desaparecer para siempre. Lo que predominaría sería la objetividad y la unidad metodológica en las ciencias, la moral y el arte. La razón poco a poco descubriría las leyes universales que rigen al macro y al microcosmos.

Después de las guerras mundiales, las crisis nucleares y los problemas ambientales no queda la menor duda de que los ideales de la modernidad no solo resultaron ser falsos, sino sumamente ingenuos. Según esto, podemos decir, de acuerdo con Gianni Vattimo, que la posmodernidad es el rebasamiento de la modernidad, aunque no compartimos la concepción de la posmodernidad como una modernidad negativa o invertida, como posteriormente lo expuso en su libro El fin de la modernidad. Nihilismo y Hermenéutica en la Cultura Posmoderna (2000). La posmodernidad resulta de la incapacidad concreta de la modernidad de cumplir sus promesas más

1 Esta afirmación es polémica, ya que generalmente los curadores de los museos o los encargados de exposiciones de arte fungen, en cierto sentido, como aquellos que determinan lo que es arte y lo que no lo es. Los primeros en función de su expertise y los segundos basados en criterios de oportunidad y/o beneficio. 
específicas. Podemos aventurarnos a decir que la modernidad misma es de alguna manera un metarrelato o, mejor dicho, el discurso de la modernidad es un metarrelato. Frente a la supuesta unidad metodológica, "la posmodernidad, en cambio, sostiene que solo pueden haber consensos locales o parciales (...) diversos juegos del lenguaje o paradigmas inconmensurables entre sî" (Díaz, 2005, p. 19). La posmodernidad desconfía de aquel progreso que declaraba la modernidad, mientras que al mismo tiempo señalaba las contradicciones del capitalismo y de las sociedades de masas.

Como se puede ver, lo conocido como posmodernidad no posee una claridad plena, ni menos aún una unitaria comprensión conceptual. De forma similar, parece incorrecto asociar la posmodernidad a un pequeño grupo de autores, o verla como una aglutinación de "novedades anacrónicas".2

Sin embargo, en lo que respecta a este texto, no pretendo de ninguna manera etiquetar a Antonin Artaud como un autor posmoderno o con ideas posmodernas. Si existe una relación de este poeta francés con la denominada posmodernidad es por su fuerte crítica a la metafísica occidental, al lenguaje nihilista y al nihilismo moral (tampoco escatima su prosa para denunciar la decadencia europea).

Artaud fue dramaturgo, poeta y actor, lo que hace que su pensamiento se recoja en una gran cantidad de poemas, cartas y textos de carácter literario en su mayoría. De forma tal que no sería extraño que, si se revisaran descontextualizadamente o de manera apresurada, parecieran a primera vista incongruentes, carentes de unidad o simplemente como los galimatías de un charlatán. De hecho, algunos de sus críticos más duros consideran que todo lo escrito por él es solamente una "retórica insubstancial, pomposa, vacía, verbalismo puro" (Mirlás, 1978, p. 101). Otros, por el contrario, creen que es "lo más grande que se ha escrito sobre el teatro del siglo XX" (Barrault, citado en Alonso. 1975, p. 15). Pero, dejando un poco de lado a los críticos que tergiversan sus ideas y a los fanáticos que las idolatran, lo cierto es que Artaud ha influenciado a personajes tan diversos como Vitrac, Ghereldore, Beckett, Vauthier, Camus, Sartre e inclusive a Derrida y Deleuze, por mencionar solo algunos.

2 Según la opinión de algunos académicos universitarios. Véase Fragomeno (2007). 


\section{Acto I: La contradicción como principio}

En Le Théâtre et son double (1999) Artaud esgrimió un rechazo total hacia el teatro occidental. Esta oposición encuentra como fundamento su desdén por la metafísica occidental, profundamente maniquea. Según su decir, este dualismo es asumido por todos los artistas europeos, y por la misma Europa en un sentido más general.

El francés se basó en una distinción que realizó entre cultura y civilización. La cultura refleja o mantiene una perspectiva más metafísica del ser humano, mientras que la civilización hace alusión a sus instituciones. Esta división aparentemente sencilla resulta fundamental para el desarrollo de sus ideas posteriores, ya que este pensamiento dicotómico se debe a una separación muy antigua. Según el francés, los pueblos más antiguos no tenían esta disociación; por el contrario, vivían inmersos en una unidad espiritual y física.

Artaud amaba considerar un pasado mítico caótico de la humanidad, cuando el mundo era formado y el hombre seguía siendo adentro tacto con las vida-fuerzas y los dioses universales que eran inmanentes en naturaleza. Durante estas grandes épocas, los fenómenos naturales incorporaron principios metafísicos de tal modo tendiendo un puente sobre la dicotomía entre la idea y el hecho, entre la mente y la materia3 (Greene, 1967, p. 190).

Al comienzo de estas épocas existían dos principios fundamentales: lo masculino y lo femenino. Al inicio estos dos principios estaban unidos, es decir, existía lo masculino-femenino. Lo masculino representado por el sol, el falo, el semen y lo femenino caracterizado por la luna, la vagina y la menstruación. En Héliogabale ou l'anarchiste couronné se comenta como en Siria estos dos principios se unían en un solo templo:

Había el templo del sol en Emesa -dice- que parecía tener primacía sobre los demás templos del sol macho, como si hubiera varios soles, cada uno de los cuales tomado en particular fuese el doble de todos los demás, de la

3 "Artaud loved to envisage a chaotic mythical past of humanity, when the world was being formed and man was still in touch with universal life-forces and gods that were immanent in nature. During these great epochs, natural phenomena embodied metaphysical principles, thereby bridging the dichotomy between idea and fact, between mind and matter". 
misma forma que la luna es el doble hembra de un dios único y masculino; y el templo del sol-luna en Apanea completamente cubierto de piedras de luna; y el de la luna en Sierápolis, cerca de Emesa, exteriormente consagrado a la mujer, que contenía un trono achaparrado y disminuido por el macho, que solamente se mostraba una vez al año y con la figura de Apolo (Artaud, 1972, p. 25).

Estas antiguas culturas mantenían un lazo estrecho con la divinidad, con el espíritu. Para ellas lo masculino podía ser femenino y lo femenino podía trastocarse en masculino. La sexualidad resultaba ser una fuerza creadora que se manifestaba en lo masculino-femenino, todo dentro de un caos perfectamente armonioso.

Para estas culturas los dioses representaban las fuerzas más básicas, caracterizando energías múltiples. De manera que sus nombres podían representar elementos "contradictorios". Sin embargo, esto no se mantuvo por mucho tiempo y los principios entraron en conflicto. Este fenómeno es considerado como producto de lo que anteriormente mencionábamos: las fuerzas múltiples. Al ser variadas, las culturas antiguas necesitaron jerarquizarlas y esto provocó lo escisión primaria:

Si los pueblos terminaron por considerar a los dioses como seres verdaderamente separados, si se equivocaron acerca del significado de esos dioses, debemos observar que cada pueblo, tomado individualmente, y en el mismo punto del espacio y el tiempo, siempre trató de organizar jerárquicamente sus poderes, y que allí donde un femenino recubrió un masculino e inversamente, en la cabeza y el corazón del pueblo que por encima de él desplegaba esos dioses contradictorios por esencia, el masculino era el masculino, y el femenino el femenino sin inversión nominal posible; quiero decir que inmediatamente el mismo nombre nunca servía a dos formas, si a uno le interesa considerar esas formas como entidades verdaderamente separadas, sino que el mismo nombre a menudo era la contracción de dos formas, hechas, aparentemente, para devorarse entre sí (Artaud, 1972, p. 50).

Este Uno que se dividía, pero siempre permaneciendo unitario, terminó por separarse. Esta separación creó todo un problema ontológico, ya que produjo a su vez lo manifestado y lo no-manifestado. Desapareció la inversión 
nominal y las cosas se volvieron estáticas, perdieron todo el fluir del caos. Desde este momento las cosas tienen un doble dicotómico, y no una sombra que formase parte del mismo cuerpo.

Artaud encontró sustento a esto en la historia de Heliogábalo. Vario Avito Basiano era hijo de un general romano (supuestamente) y de una mujer cuya ascendencia se remonta a las antiguas culturas sirias, en las cuales el sol servía de principio unificador. Desde pequeño fue consagrado al culto del dios solar Baal y llegó a ser sumo sacerdote. Debido a esto pasó a ser conocido como Elagabal o Heliogábalo (según la trascripción griega). Tiempo después, por medio de una serie de ardides y manipulaciones de su abuela Julia Mesa (o Maesa), este llegó a ser emperador de Roma a la edad de catorce años. Lo importante de este relato es que Heliogábalo "restauró" el orden cósmico originario al destruir todas las otras expresiones religiosas de Roma y fundirlas a todas ellas en el culto solar de Baal. Esta unificación de contrarios no fue fácil, ya que se llevó a cabo con mucha violencia y con actos de crueldad desmedida. Crueldad que es inherente al caos originario y a la misma naturaleza humana.

Heliogábalo resultó ser un anarquista, porque rechazaba todo el orden establecido. Rechazó hasta su propio nombre (el mismo Artaud también lo hizo en su momento), ya que pidió que se le llamara Heliogábalo, y no por su nombre romano. El anarquismo se dice sin dios, ni amo. Heliogábalo dijo yo soy mi dios y mi amo, y eso se demuestra en sus excesos y despilfarros durante el tiempo que fue emperador.

Este Uno lo buscó en las religiones “paganas” antiguas:

De hecho, él buscó constantemente las realidades espirituales y metafísicas en las cuales la dualidad que consideró entre la materia y la mente, cuerpo y el alma, hecho e idea, podría ser reconciliada. Su deseo de encontrar un principio para superar la dualidad está en la base de su fascinación de las varias doctrinas místicas y religiones esotéricas ${ }^{4}$ (Greene, 1967, p. 189).

Ahora bien, partiendo de las ideas anteriores puedo acercarme al tema del teatro y su propósito. Según Artaud, la función del teatro es doble.

4 "Indeed, he constantly sought spiritual and metaphysical realities in which the duality he saw between matter and mind, body and soul, fact and idea, could be reconciled. His desire to find a principle transcending the duality is at the base of his fascination for various mystical doctrines and esoteric religions". 
Primero, brindar esta unidad en el plano de la representación y, segundo, crear una catarsis metafísica por medio de la crueldad.

Con relación al primer punto, el teatro es el lugar donde se da una expiación ritual. Por ejemplo, en el théâtre de la cruauté lo que se busca es una cópula entre estos dos principios, una cópula que es violenta y sangrienta. Para este poeta francés, la sangre representa el constante fluir, significando la vida misma. Así como la disgregación de estos principios se dio inicialmente por medio de un combate, así mismo debe ser su unificación, y es por esto que en el teatro de la crueldad siempre está latente el conflicto. Esto es así, además, por la naturaleza misma del teatro. El teatro de la crueldad consiste en representar, concepto que se diferencia de la mimesis: "El Arte no es la imitación de la vida, sino que la vida es la imitación de un principio trascendente con el que el arte nos vuelve a poner en comunicación" (Artaud, citado por Derrida, 1989, p. 3). La re-presentación consiste en plasmar de nuevo las fuerzas destructivas ${ }^{6}$ de lo femenino y de lo masculino, y no simplemente evitarlas. Esta representación no debe ser confundida con una mise en scène. "El Teatro de la crueldad no es una representación. Es la vida misma en lo que ésta tiene de irrepresentable. La vida es el origen no representable de la representación" (Derrida, 1989, p. 3). Este teatro busca recuperar aquello que Occidente ha perdido: la comunión con la realidad más originaria.

Artaud sueña con una unión mística del hombre y del cosmos en que aniquilen y hagan uno al individuo, como tal, con las fuerzas universales. Enajenándose de la naturaleza, el hombre europeo había perdido de vista su posición de vista metafísica y había funcionado en desarmonía con las fuerzas cósmicas? (Greene, 1967, p. 190).

Para esto el actor solo deberá utilizar los gestos, los sonidos y los movimientos, sustrayéndose de las palabras y del texto.

5 De hecho, Artaud pretendió eliminar aquella concepción que ve al arte como imitación.

6 Sobre esta idea, Artaud pareció acercarse al concepto destruktion heidegeriano.

7 "Artaud's dream of a mystical union of man and the cosmos in which the individual, as such, is annihilated and becomes one with universal forces. By alienating himself from nature, European man had lost sight of his metaphysical position and no longer functioned in harmony with cosmic forces". 
Pero el teatro verdadero, ya que se mueve y utiliza instrumentos vivientes, continúa agitando sombras en las que siempre ha tropezado la vida. El actor que no repite dos veces el mismo gesto, pero que gesticula, se mueve y por cierto maltrata las formas, detrás de esas formas y por su destrucción recobra aquello que sobrevive a las formas y las continúa (Artaud, 1999, pp. 14-15).

En este sentido, el teatro apunta a la realidad metafísica y busca ser una manifestación de eso que sobrevive a las formas.

La segunda característica del théâtre de la cruauté es la de proveer una catarsis. Para esto el teatro utiliza la crueldad. Artaud, en una carta que escribió para su amigo Jean Paulhan, precisó su significado:

La crueldad es sobre todo necesidad y rigor. La decisión implacable e irreversible de transformar al hombre en un ser lúcido. De esta lucidez nace el nuevo teatro. Todo nacimiento implica también una muerte. Para dar origen a mi "crueldad" será necesario cometer un asesinato. Hay que asesinar al padre de la ineficacia en el teatro: el poder de la palabra y del texto. El texto es el dios todopoderoso que no le permite al verdadero teatro nacer. $\mathrm{Al}$ atentar contra la palabra, atentamos contra nosotros mismos. Hasta ahora, es el lenguaje verbal aquello que nos permite comprender al mundo. $\mathrm{Y}$ lo comprendemos mal. $\mathrm{Al}$ asesinar al lenguaje verbal, estamos asesinando al padre de todas nuestras confusiones. Por fin seremos libres. Esto vale no sólo para el teatro. Seremos hombres libres en todo aspecto de nuestra vida (Artaud en Garrido, 2005).

De igual manera, en Le Théâtre et son double esto queda impreso con mayor fuerza:

En el plano de la representación, no se trata de esa crueldad que podemos ejercer unos contra los otros despedazando nuestros cuerpos, mutilando nuestras anatomías personales (...) sino aquella crueldad mucho más terrible y necesaria que las cosas pueden ejercer contra nosotros. No somos libres. Y el cielo puede caernos sobre la cabeza. Y el teatro está hecho para enseñarnos eso (Artaud, 1999, p. 18).

De esta manera, el actor y dramaturgo francés consideró que la crueldad es un elemento vital y creador que en el teatro sirve como una catarsis metafísica. Todo el conflicto y la agonística de los principios universales se 
purgan en el teatro. En el teatro se presenta una crueldad ficticia para purgar nuestros deseos crueles y nuestros instintos violentos. "Una acción violenta y a presión es una semejanza de lirismo: evoca imágenes sobrenaturales, una sangre de imágenes, y un chorro sangrante de imágenes tanto en la del poeta como en la del espectador" (Artaud, 1999, p. 21). A manera de ejemplo se podría decir que el actor comete un crimen ficticio para que el espectador no cometa uno real.

\section{Acto II: "La lengua es una puta obscena"}

Siguiendo una línea ya señalada por Kierkegaard, Nietzsche o Heidegger, Artaud creía que el lenguaje oculta cualquier posible vínculo con el ser verdadero o con la realidad más íntima. Noami Greene consideró que:

Él creyó que ningún escritor que utilizara tradicionalmente la lengua podría revelar las verdades metafísicas al hombre, porque la lengua ordinaria obscureció las realidades espirituales del universo. La decadencia cultural de Europa fue relacionada de cerca con una degeneración lingüística, en la cual la lengua se había separado totalmente del ser real de $\operatorname{cosas}^{8}$ (Greene, 1967, p. 191).

En la descripción hecha por el francés el lenguaje no tiene ninguna legitimación ontológica. Es un intruso en el ser humano, un intruso en el ser. El lenguaje, especialmente el escrito, aliena al ser humano, lo aleja de las verdades más originarias y lo envuelve en un marasmo de conceptos muertos, de dualidades sin sentido. La lengua nos enajena de tal manera que el concepto se llega a sustancializar y creemos que el concepto-palabra tiene alguna relación verdadera con la naturaleza. A este fenómeno le llamó idolatría y lo catalogó como simplemente indecente: "la lengua es una puta obscena" dijo en cierto momento (citado por Dumoulié, 1996, p. 95). En concordancia con Nietzsche, el francés opinaba que nuestro miedo al sin sentido, a la oscuridad, al hoyo es el que nos hace inventar esas falsas

8 "He believed that any writer who used language traditionally could not reveal metaphysical truths to man, for ordinary language obscured the spiritual realities of the universe. Europe's cultural decadence was closely related to a linguistic degeneration, in which language had become completely separated from the actual being of things". 
verdades. Estas "verdades maternales" nos alejan de una relación directa con lo real, nos alejan del sentido, del vacío.

Este lenguaje posee per se una fuerza represiva, una fuerza furtiva que llega a reprimir la crueldad originaria, la crueldad de la que nació todo. Esta fuerza que se menciona es dios. Lo que se pretende es liberar al lenguaje de dios, del concepto.

En una serie de cartas escritas en la etapa surrealista de Artaud (recogidas como Cartas a los poderes) se declara una guerra a esta gramática nihilista:

Basta de juegos de palabra, de artificios de sintaxis, de malabarismos formales; hay que encontrar -ahora- la gran Ley del corazón, la Ley que no sea una ley, una prisión, sino una guía, para el Espíritu perdido en su propio laberinto"9 (Artaud, 1978, p. 10).

Esta cárcel, esta prisión, es Dios. Ese ser cuya esencia es el logos o la palabra creadora. El logos humano no está exento de estos problemas, ya que se cree que es el que le da sentido a las palabras, al lenguaje, cuando en realidad es anterior (o por lo menos se da al mismo tiempo). En un pasaje de marcadas resonancias heideggerianas dijo que: "Ese discurso por el cual me expreso cuando hablo y que imagino que conduzco, en realidad me conduce, y eso es lo enloquecedor" (Artaud, citado por Dumoulié, 1996, p. 98).

Cuando el concepto se solidifica se produce la máxima expresión de la degradación ontológica y el espíritu se vuelve un cementerio. La lengua es un callejón sin salida que solo da cuenta de sus propias reglas lógico-formales. El lenguaje solo dice lo que anteriormente ha puesto él mismo para decir. El mundo se vuelve absolutamente carente de ser. El fondo de nuestro ser es tan obscuro y extraño que incluso es comparado con un $c u,{ }^{10}$ un "hoyo siempre sucio por la metafísica y por Dios que no dejan de invadirlos" (Artaud, citado por Dumoulié, 1996, p. 101); dios se entromete tanto en nuestro cuerpo y en nuestros pensamientos que prácticamente nos viola.

9 Este texto aparece específicamente en el documento intitulado Carta a los rectores de las universidades europeas.

10 Artaud suprimió la "l" final de la palabra "cul", que traducida literalmente es "culo". Esta analogía no proviene solamente de una "etapa anal", sino que pretende devolverle el poder creador a la palabra, no como palabra sino como sonido. Sonido que puede provocar y recordar las experiencias más originarias y vitales: las violentas y las crueles. Esto se relaciona de igual manera con la experiencia catártica metafísica del teatro de la crueldad. 
Uno de los conceptos más engañosos es el moi (yo), puesto que da una idea de continuidad y sustancialidad totalmente inexistente. El yo es una realidad ficticia que se basa en el principio de contradicción, el yo no puede ser no-yo. Separando el sujeto del objeto, creando un adentro y un afuera. Esta separación es producto de la metafísica. En última instancia, este yo es como el arjé griego, el principio del cosmos. Un fundamento que resulta ser falso. Pero el yo no es un fundamento, más bien el fundamento del yo es el cu. En el cu no hay separación entre un adentro y un afuera. En el cu habita y "habla" la carne, la sangre y la crueldad más básica, ahí se da la crueldad liberadora que tanto mencionaba el poeta francés. El yo-sujeto es enajenante y, de nuevo, sencillamente obsceno.

$\mathrm{Si}$ existe algo como un yo es un proceso, un proceso cruel y violento en extremo. Según este poeta francés nunca se es plenamente, sino que, en un sentido estricto, se es lo que se puede ser. Pero este poder-ser es violento, porque se basa en el caos y en las diferencias más crueles.

Al principio del L'ombilic des limbes se anota lo siguiente:

Sufro que el Espíritu no esté en la vida y que / la vida no esté en el Espíritu, sufro del Espíritu órgano, / del Espíritu-traducción, o del Espíritu intimidación- / de-las-cosas para hacerlas entrar / en el Espíritu.

Yo pongo este libro suspendido en la vida, deseo / que sea mordido por las cosas exteriores y / antes que nada por todos los sobresaltos en acecho, / todas las oscilaciones de mi yo por venir. ${ }^{11}$

Todas estas páginas se arrastran como témpanos / en el espíritu. Disculpen mi absoluta / libertad. Me rehúso a hacer diferencias entre / cada uno de los minutos de mí mismo. No reconozco / el espíritu planificado (Artaud, 2002, p. 2).

Este "yo por venir" es el único yo, no una abstracción dentro de un “espíritu planificado”. Artaud encontró una forma para desenajenarse de este yo. La encontró en un proceso que nunca acaba, pero que siempre comienza. El proceso consiste en rechazar, como Heliogábalo, de una manera anárquica cualquier tipo de identidad. En un poema llamado "J'étais vivante..." hizo mención de lo anterior: «Nada de boca / nada de lengua / nada de dientes

11 La negrita es del original. 
/ nada de laringe / nada de esófago / nada de estómago / nada de vientre / nada de ano /Yo reconstruiré al hombre que soy. ${ }^{12}$ (Artaud en Derrida, 1989b pp. 259).

El yo gramatical que se sustancializa no puede existir. Es una imposición del otro, de los otros que también creen ser yos. El nombre mismo de Antonin Artaud fue una imposición, él nunca lo escogió. Es por esto que para conseguir su verdadera identidad comenzó por nombrarse él mismo, es decir, por ponerse un nuevo nombre. Para esto comenzó jugando con su apellido. En varios de sus textos escribió Ar Tau, a.r.t.o. y otras combinaciones. Lo esencial de esto radica en la reconstitución de su "verdadero yo" por medio de una actitud que parece poco racional y que, por el contrario, se parece mucho a la locura.

El loco 'en celo' se vuelve progenitor de sí mismo y de su yo, como de sus hijas siempre por venir. Sin regreso a un sí arquetípico, puede sin embargo desbordar los marcos alienantes del sujeto y de su temporalidad cerrada, para reconstruir su "identidad. (Dumoulié, 1996, pp.129

Convirtiéndose cada vez en autor de su propio nacimiento, Artaud escribió: "Yo, Antonin Artaud, yo soy mi hijo, mi padre, / mi madre / y yo" (citado por Dumoulié, 1996, p. 129). Artaud buscó ser la génesis de él mismo.

Retomando el tema del lenguaje, Artaud buscaba una revolución lingüística que diera cuenta de nuestro verdadero ser. "Para alcanzar una revolución espiritual debemos primero entender la naturaleza verdadera de nuestro ser $(\ldots)$ una comprensión que se debe preceder por un cambio radical en nuestra lengua"13 (Greene, 1967, p. 191). Esta labor debe ser llevada (o es llevada) por el teatro. En Le Théâtre et son double se muestra cómo debe ser llevado a cabo esto. La única manera de conseguirlo es por medio de la crueldad. Esto es lo que él denominó le théâtre de cruauté, pero como una condición previa a esto es necesaria la destrucción. La destrucción se lleva a cabo por medio de gestos, movimientos bruscos y violentos, eliminando

12 «Pas de bouche / Pas de Langue / Pas de dents / Pas de larynx / Pas d'oesophage / Pas d'estomac / Pas de ventre / Pas d'anus /Je reconstruirai l'homme que je suis».

13 "In order to achieve a spiritual revolution we must first understand the true nature of our being - an understanding that must be preceded by a radical change in our language". 
el texto del teatro y las palabras de la interpretación, un lenguaje en el que las fuerzas violentas más originarias salen a flote.

Tanto para el teatro como para la cultura, queda abierta la cuestión de nombrar y dirigir las sombras: y el teatro, que no se fija en el lenguaje ni en las formas, destruye por ese hecho las sombras falsas, pero prepara el camino para otro nacimiento de sombras en torno de las cuales se congrega el verdadero espíritu de la vida.

Destruir el lenguaje para tocar la vida es hacer o rehacer el teatro (Artaud, 1999, p. 11).

En este pasaje se menciona el poder creador del lenguaje. Artaud, al igual que Nietzsche,${ }^{14}$ creía en la capacidad de un lenguaje móvil que diera $\mathrm{fe}$-de alguna manera- de ese fondo real, de esa X incognoscible. Este lenguaje creador es asociado a los gestos. En este punto, siguió una postura un poco desconocida de Nietzsche. En el fragmento póstumo 1[28] Nietzsche mencionó que: "Todos los movimientos han de ser considerados como gestos, una especie de lenguaje en que el que se entienden las fuerzas (... L Lo esencial es: la formación de formas que representen muchos movimientos, la invención de signos para especies enteras de signos" 15 (Nietzsche, citado por Llinares, 1988, p. 204). De igual manera, Artaud mencionó que:

El teatro que no está en nada pero que se sirve de todos los lenguajes: gestos, palabras, sonidos, fuego, gritos, se encuentra exactamente en el punto en que el espíritu tiene necesidad de un lenguaje, para producir sus manifestaciones. Y la fijación del teatro en un lenguaje: palabras escritas, música, luces, ruidos, indica rápidamente su pérdida (Artaud, 1999, pp. 11-12).

Esto queda más claro aún en un fragmento del Teatro de la crueldad. Primer Manifiesto:

Este lenguaje no puede definirse sino como posible expresión dinámica y en el espacio, opuesta a las posibilidades expresivas del lenguaje hablado. Y

\footnotetext{
14 Las similitudes entre Artaud y Nietzsche son considerables. Sin embargo, por la naturaleza temática de este escrito, dichas semejanzas no son tratadas en este texto.

15 La cursiva es del original.
} 
el teatro puede utilizar aún de este lenguaje sus posibilidades de expansión (más allá de las palabras), de desarrollo en el espacio, de acción disociadora y vibratoria sobre la sensibilidad. Aquí interviene en las entonaciones, la pronunciación particular de una palabra. Aquí interviene (además del lenguaje auditivo de los sonidos) el lenguaje visual de los objetos, los movimientos, los gestos, las actitudes, pero sólo si prolongamos el sentido, las fisonomías, las combinaciones de palabras hasta transformarlas en signos, y hacemos de esos signos una especie de alfabeto. Una vez que hayamos cobrado conciencia de ese lenguaje en el espacio, lenguaje de sonidos, gritos, luces, onomatopeyas, el teatro debe organizarlo en verdaderos jeroglíficos, con el auxilio de objetos y personajes, utilizando sus simbolismos y sus correspondencias en relación con todos los órganos y en todos los niveles (Artaud, 1978, pp. 101-102).

Tanto Nietzsche como Artaud hicieron referencia a una especie de lenguaje pre-verbal. En el caso concreto de este último, el lenguaje de la carne, los signos del cuerpo. El teatro debería, por lo tanto, poder mostrar al ser humano en su nivel pre-verbal, antes de la lógica gramatical. Lo que se pretendía era revolucionar la lengua devolviéndola a su estado originario, su estado pre-lingüístico. Sin embargo, esto no quiere decir que debamos caer en un mutismo o que Artaud debía renunciar a escribir, sino que se busca utilizar al lenguaje de una manera distinta a la tradicional. Utilizaré como ejemplo el siguiente poema, que aparece en Artaud le Mômo:

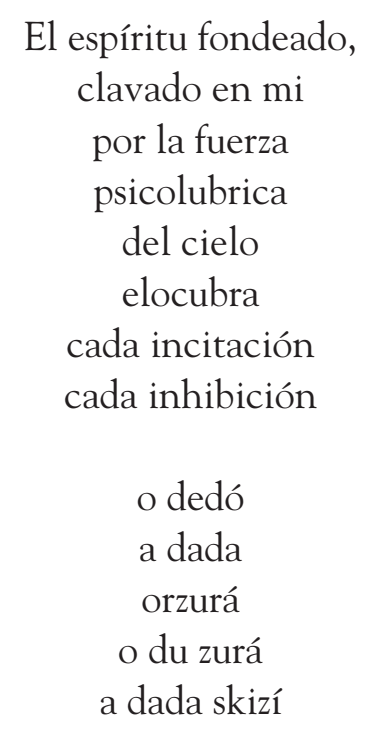




\author{
o kayá panturá \\ o ponurá \\ o pená \\ poní \\ Es la telaraña pentral \\ la pela onura \\ de o-o la vela \\ la lámina anal de anavú \\ (Artaud, 1998, pp. 13-14).
}

Si se lee este poema en voz baja puede que no nos diga mucho, o nada. Pero si se lee en voz alta (por lo menos en su versión original en francés) se notará que los sonidos se enlazan como si fuera un juego. Esta técnica es utilizada por el francés en muchos de sus escritos: tensionar las palabras para producir ciertos sonidos. De igual forma, este poema está estructurado de tal manera que produce imágenes y evoca sensaciones ${ }^{16}$, muchas de ellas grotescas. "Los sonidos pueden incluso no sugerir palabras reales, pero pueden despertar simplemente ideas o emociones"17 (Greene, 1967, p. 196).

Artaud experimentó mucho con los sonidos de las palabras y las imágenes que estas podían producir. Gran parte de su vida consideró que la única forma en la que el lenguaje verbal y escrito (y en este sentido la escritura teatral) perdiera su fuerza alienante sería por medio de un nuevo sentido. Sentido que

No ocupará ya el lugar limitado de una notación de palabras, cubrirá más bien todo el campo de ese nuevo lenguaje: no solo la escritura fonética y transcripción del habla, sino escritura jeroglífica, escritura en la que los elementos fonéticos se coordinan con elementos visuales, pictóricos, plásticos (Derrida, 1989, p. 8).

\footnotetext{
16 Esta técnica es muy utilizada en la poesía en general; se le conoce como kinestesia. Es común encontrar en los textos de Artaud, además, una gran predilección por los sonidos onomatopéyicos.

17 "Sounds may not even suggest actual words, but may merely awaken ideas or emotions".
} 
Sin embargo, en sus últimos años de vida desechó este método como forma de liberación y consideró que lo que ataba verdaderamente al ser humano para conocer la realidad más íntima era el cuerpo mismo.

\section{Acto III: Un cuerpo sin órganos}

Si se viera el cuerpo como un texto se podría decir que en él se da al mismo tiempo la relación de sentido-referencia. "La carne es una especie de escritura viviente donde las fuerzas imprimen 'vibraciones' y excavan 'caminos'; en ella el sentido se despliega” (Dumoulié, 1996, p. 134).

En la primera etapa del actor francés, el cuerpo era el eje en el que se basaba toda la comprensión y aprensión originarias, el lugar donde la realidad más íntima podía manifestarse. Era el lugar mismo del sentido. Sin embargo, Artaud en sus últimos escritos se alejó de esta postura, y fue el cuerpo el lugar en el que enfocó sus misiles. Estas ideas aparecen con fuerza en el escrito llamado Para terminar con el juicio de Dios y otros poemas, en este escrito se menciona que:

Existía en otros tiempos una operación de orden menos mágico que científico y que el teatro sólo consigue rozar, por la cual el cuerpo humano cuando se lo reconocía como malo era pasado, transportado, física y materialmente, objetiva y como molecularmente de un cuerpo a otro, de un estado pasado y perdido de cuerpo a un estado fortalecido y elevado del cuerpo.

Y bastaba para ello dirigirse a todas las fuerzas dramáticas, rechazadas y perdidas del cuerpo humano.

Se trata así realmente de una revolución y todo el mundo requiere una revolución necesaria, pero yo no sé si muchas gentes han pensado que esa revolución no sería verdadera mientras no sea física y materialmente completa, mientras no sé dirija al hombre, hacia el cuerpo del hombre mismo y no se decida por fin a pedirle que se cambie.

Pues el cuerpo humano se ha tornado sucio y malo porque vivimos en un mundo sucio y malo que no quiere que el humano sea cambiado (Artaud, s.f, p. 82-83).

El cuerpo es un escollo para el "verdadero cuerpo", para un "cuerpo puro". El cuerpo es el causante de producir ideas falsas y de crear la dualidad entre mente y cuerpo; estas ideas son producto del cuerpo y, por lo tanto, 
el cuerpo es la génesis de dios. "Las ideas no son sino el vacío del cuerpo. Interferencias de ausencia y de carencia, / entre dos movimientos de realidad explosiva, / que el cuerpo por su sola presencia nunca ha dejado de imponer" (Artaud, citado por Dumoulié, 1996. p. 140).

Ahora, yo estimo que necesitamos saber, y que no necesitamos más que saber. Si pudiéramos amar, amar de un solo golpe, la ciencia sería inútil; pero hemos desaprendido a amar, por acción de una especie de ley mortal que proviene de la gravedad misma y de la riqueza de la creación. Estamos en la creación hasta el cuello, estamos ahí dentro por todos nuestros órganos: los sólidos y los sutiles. Y es difícil remontar a Dios por el camino escalonado de órganos, cuando esos órganos nos fijan en el mundo en que estamos y tienden a hacernos creer en su exclusiva realidad. El absoluto es una abstracción, y la abstracción requiere una fuerza que es contraria a nuestro estado de hombres degenerados. ${ }^{18}$ (Artaud, 1979, p. 56).

De nuevo, el francés consideró que de lo que se trata es de destruir el cuerpo. Siguiendo una serie de ideas anteriores, también determinó que existe un cuerpo obsceno y un cuerpo puro. El cuerpo obsceno es el cuerpo sucio, donde siempre existe dios y su logos. El cuerpo puro es un cuerpo sin dios, sin sentidos, un cuerpo sin órganos. A pesar de esto, el cuerpo sigue siendo la única realidad, una realidad inmortal. En una de las ideas de Para terminar el juicio de Dios y otros poemas aparece la siguiente afirmación:

Pues nadie en este momento -dice Artaud- puede creer que un cuerpo pueda cambiar si no es por el tiempo y la muerte. Ahora bien, yo repito que la muerte es un estado inventado y que sólo vive por todos los miserables brujos, los gurús de la nada a quienes beneficia y quienes desde hace siglos se nutren de él y viven en el estado llamado Bardo. Fuera de esto el cuerpo humano es inmortal (Artaud, s.f, p. 81).

18 "Or, j'estime que nous avons besoin de savoir, et que nous n'avons besoin que de savoir. Si nous pouvions aimer, aimer d'un seul coup, la science serait inutile ; mais nous avons désappris à aimer, sous l'action d'une sorte de loi mortelle qui provient de la pesanteur même et de la richesse de la création. Nous sommes dans la création jusqu'au cou, nous y sommes par tous nos organes: les solides et les subtils. Et il est dur de remonter à Dieu par le chemin échelonné des organes, quand ces organes nous fixent dans le monde où nous sommes et tendent à nous faire croire á son exclusive réalité. L'absolu est une abstraction, et l'abstraction demande une force qui est contraire à notre état d'hommes dégénérés" 
Este "cuerpo sin órganos" no es una invención ontológica, ni tampoco un concepto. Es una paradoja, es un principio unitario en el cual no existe la diferencia, tal y como lo señalé al inicio de este ensayo. En este punto se está como al inicio, en la búsqueda de la unidad antes de la separación de los contrarios. Este anhelo consumió toda la vida de Artaud, su vida fue cruel y por eso mismo autentica.

\section{Epílogo}

Artaud intentó, a lo largo de su vida, exorcizar los demonios de Occidente. Sus escritos, más que tratados de teatro o técnicas para la dramaturgia, son claras diatribas contra la sociedad occidental y sus ideales modernos. Esta lucha metafísica se desarrolló principalmente en el plano artístico. La perversión que ha sufrido el teatro al convertirse en una mera copia del texto escrito -según él- solo demuestra cómo la sociedad ha perdido cualquier contacto con los principios vitales más originarios. Esta desvitalización se debe en gran parte al Dios-logos que ha terminado por ontificar la realidad, haciendo, inclusive, que nuestro conocimiento más propio comience por re-conocernos como cosas (je-moi). El lenguaje ha perdido todo su poder creador y lo único que produce ahora son tótems que nos encadenan más a nuestras ficciones. Violencia, crueldad, sangre son solo algunos ejemplos metafóricos que el francés utilizó para intentar revertir el nihilismo sobre el que sustentamos nuestras "verdades".

Todos estos temas son obvios reproches a la modernidad y a sus cándidas promesas. Pero esto no basta para decir que Artaud fue "posmoderno". Si efectivamente sus planteamientos poseen alguna relación con la posmodernidad no se debe a alguna supuesta "filiación espiritual" a la misma, sino a la destrucción que ambos plantean. Quizá el mayor legado de Antonin Artaud no sean sus aportes al teatro, sino mostrarnos la vida como una hemorragia... 


\section{Bibliografía}

Alonso, R. (Ed.) (1975). ¿Quién conoce a Antonin Artaud? Buenos Aires, Argentina.

Artaud, A. (1972). Heliogábalo o el anarquista coronado (trad. Carlos Manzano). Madrid, España: Editorial Fundamentos.

Artaud, A. (1978). El teatro de la crueldad. Primer manifiesto. Recuperado de: www.scribd. com/doc/6544616/Primer-Manifiesto-Del-Teatro-de-La-Crueldad

Artaud, A. (1998). El regreso de Artaud El momo. Recuperado de: www.librodot.com

Artaud, A. (1999). El teatro y su doble. Edhasa. Barcelona

Artaud, A. (s.f) Para terminar con el juicio de Dios y otros poemas. Recuperado de: www. librostauro.com.ar

Artaud, A. (2003). Carta a los poderes. Editorial Argonauta. Argentina.

Artaud, A. (s.f) El ombligo de los limbos. Recuperado de: http://www.revistakatharsis.com/ bv_sm_autores_A-1Artaud.html Consultada el 5 de octubre del 2013

Derrida, J. (1989). El Teatro de la crueldad y la clausura de la representación. Recuperado de: www.jacquesderrida.com.ar/textos/artaud_1.htm

Derrida, J. (1988b). La escritura y la diferencia. Editorial Anthropos. Barcelona. España.

Díaz, E. (2005). Posmodernidad. Buenos Aires, Argentina: Biblos.

Dumoulié, C. (1996). Nietzsche y Artaud: por una ética de la crueldad. México: Siglo XXI.

Fragomeno, R. (2007). Novedades anacrónicas. (Respuesta a la pregunta: ¿Qué fue la posmodernidad?). En Praxis: Revista de la Escuela de Filosofía-Nº 60, pp-179-186.

Garrido, A. (2005). El teatro sagrado. Revista Teína N7. Enero-Febrero-Marzo 2005. Versión electrónica http://www.revistateina.es/teina/web/teina7/tea1.htm Consultada el 2 noviembre del 2013

Jameson, F. (1995). El postmodernismo o la lógica cultural del capitalismo avanzado. Barcelona, España: Ediciones Paidós.

Jiménez, A. (Comp.) (1993.) Del búho a los Gorriones. Ensayos sobre la postmodernidad. San José: Guayacán.

Knapp, B. (1964). Artaud: A New Type of Magic. En Yale French Studies, No. 31, Surrealism, pp 87.98. http://dx.doi.org/10.2307/2929726

Llinares, J. (Ed.) (1988). Nietzsche. Antología. Barcelona, España: Ediciones Península.

Lyotard, J. F. (1998). La condición postmoderna (trad. Mariano Antolín Rato). Madrid, España: Ediciones Cátedra.

Mirlás, L. (1978). Artaud y el teatro moderno. Buenos Aires, Argentina: El Ateneo.

Vattimo, G. (2000). El Fin de la modernidad. Nihilismo y hermenéutica en la cultura postmoderna. Barcelona, España: Gedisa.

Greene, N. (1967). Antonin Artaud: Metaphysical Revolutionary. Yale French Studies, No. 39, Literature and Revolution. Yale University Press. Pp.188-197. http://dx.doi. org/10.2307/2929492 